\title{
UM FRAMEWORK PARA A CRIAÇÃO E AVALIAÇÃO DE PERSONAGENS PARA GAMES NARRATIVOS
}

\author{
Melissa Streck \\ Universidade Federal do Rio Grande do Sul \\ mstreck@gmail.com \\ Suely Fragoso \\ Universidade Federal do Rio Grande do Sul \\ suelyfragoso@ufrgs.br
}

\begin{abstract}
Resumo: Este artigo trata do Design de Personagens para games narrativos. O ponto de partida é uma revisão da literatura sobre personagens em diferentes meios, utilizada como base pelos autores precedentes no tratamento da questão dos personagens para games. A seguir, identifica-se o que é próprio dos games e os diferencia dos outros meios, o que permite chegar ao diferencial dos personagens de games em relação aos dos demais meios narrativos. A partir daí, recuperam-se os trabalhos de diversos autores para apresentar os elementos e fatores centrais do Design de Personagens para games. Destaca-se a importância do Design Emocional para a criação de personagens. Ao final, esses achados são reunidos em uma grade de referência que serve como framework para a criação de novos personagens de games e avaliação de personagens existentes.
\end{abstract}

Palavras-chave: design de emoção, design de games, design de personagens.

\begin{abstract}
This article is about Character Design for narrative games. The departure point is a literature review about characters in various media, upon which previous authors who discussed game characters have based their own work. Follows a section that identifies what is proper to games and differentiates them from other media, leading to the diference between game characters and characters in other narrative media. The works of several authors allow for the identification of the central elements and factors of Character Design for games. The importance of Emotional Design for the creation of characters is noted. Finally, these findings are aggregated in a framework for the creation of new game characters or the evaluation of existing characters.
\end{abstract}

Keywords: emotion design, game design, character design. 


\section{INTRODUÇÃO}

De acordo com alguns autores (Egri, 1960; Isbister, 2006; Sheldon, 2004), a criação de um personagem vai muito além das especificações de sua aparência. 0 Design de Personagens envolve muitas variáveis, especialmente quando se trata da criação para narrativas, cujo ritmo e fascínio depende diretamente do vínculo afetivo que o público estabelece com os personagens. A questão é ainda mais complexa no caso do Design de Personagens para games, em que a interatividade afeta as relações entre o jogador e os personagens. Este artigo propõe-se a traçar uma linha que vai da construção de personagens num âmbito geral até a construção de personagens específicos para games narrativos. No percurso entre esses dois pontos, percebe-se a centralidade do Design Emocional para o Design de Personagens. Desenvolve-se então a questão do Design de Personagens para games, descrevendo os elementos e fatores que o apoiam. Ao final, os diversos tópicos discutidos ao longo do texto são agregados em uma grade referência para a criação ou avaliação de personagens.

Vale acrescentar que existem diferentes tipos de games, porém este texto trata apenas de games narrativos, nos quais os personagens fazem parte de uma estória que é facilmente identificável e que é central na relação entre o jogador e o jogo ${ }^{1}$.

\section{DESIGN DE PERSONAGENS}

A criação de personagens não nasceu com os games, e a literatura sobre a construção de personagens para meio digital lança mão do conhecimento já estabelecido para dar conta da complexidade adicional acrescentada pela interatividade.

\subsection{Personagens e Narrativas em Diferentes Meios}

A construção de personagens já foi estudada em outras áreas antecessores aos games, como teatro, cinema e literatura. Em todos esses meios, o envolvimento com a narrativa é função de vários fatores, entre os quais os personagens são um elemento central. Uma referência bastante utilizada pelos autores que tratam de personagens para games, entre eles Sheldon (2004) e Lankosky (2010), é a estrutura proposta inicialmente por Egri (1960, p. 36) para a construção de personagens envolventes. Conforme essa estrutura, a composição de um personagem é constituída de fatores fisiológicos, sociológicos e psicológicos. Egri defende que é preciso tentar encontrar todos os elementos de cada uma dessas facetas que estão por trás de um personagem. O autor tratava do caso de peças teatrais, nas quais destacava que o personagem é o material fundamental com o qual se irá trabalhar. Por isso mesmo, considerava necessário conhecer de modo bastante aprofundado os personagens (Egri, 1960, p. 32).

A primeira das dimensões de um personagem enumerada por Egri trata dos aspectos fisiológicos, que diz respeito às características físicas, que tornam cada ser visualmente diferente dos outros. Conforme Egri (1960), o sexo, a idade, o peso e

\footnotetext{
${ }^{1}$ Este alerta é relevante na medida em que é possível argumentar que todo jogo é narrativo, pois mesmo nos jogos mais abstratos sempre é possível criar um enredo para os acontecimentos, (os blocos que aparecem no jogo Tetris $^{1}$ são extraterrestres caindo de uma nave, por exemplo). Entende-se que essa discussão pertence a outras áreas de estudo, que não o Design.
} 
altura, cor de cabelos, olhos e pele, a postura, aparência e demais atributos físicos fazem parte desta dimensão. Sheldon (2004, p. 38) comenta que estas características apresentam, pela via da construção gráfica, a personalidade do personagem e até mesmo as suas funções no jogo.

A dimensão sociológica reflete o contexto social em que o personagem se encontra, além de seu tratar de seu passado, sua história pessoal, que pode contribuir para situá-lo em determinada ação (Sheldon, 2004, p. 38). Também fazem parte da construção do personagem outras facetas do seu background, que incluem sua educação, religião, nacionalidade, posição na comunidade, preferências (Egri, 1960). A composição desses fatores deverá refletir-se sobre as interações e na construção de relações com outros personagens. Este é um importante aspecto para o Design de Personagens, que mesmo no caso dos personagens mais fantasiosos traz modelos de interação do mundo real para o mundo ficcional.

No que diz respeito à dimensão psicológica de personagens de um contexto narrativo, Sheldon (2004, p. 40) defende que a personalidade de cada personagem vai sendo revelada através de suas ações. Segundo o autor, o momento certo para esse tipo de revelação é um momento de crise. Isso vincula a dimensão psicológica à anterior, a sociológica: em uma ficção bem construída espera-se que o personagem seja capaz de manter as aparências nos períodos de tranquilidade, como ocorre na vida real. Enquanto tudo está indo bem, é mais fácil agir e portar-se conforme se deseja, ou, na expressão de Goffmann (1985) manter-se fiel à máscara que se deseja apresentar no 'frontstage'. Durante os períodos de dificuldade e crise, algumas atitudes que seriam restritas ao backstage acabam aparecendo no frontstage, mostrando aos demais (ou ao público) facetas da personalidade ou da condição de vida que pretendia-se manter escondidas. Isso vai ao encontro de Palmer (2004, p. 174) que, tratando da literatura, argumenta que o leitor coleta referências isoladas, através das menções feitas de um personagem e, através da composição delas terá, ao final, uma ideia própria de como este personagem é.

A romancista britânica Virginia Woolf trouxe a ideia de que um personagem literário interessante não é aquele com o qual o leitor estabelece uma relação contemplativa, mas sim, aquele que permite que ele se colocar em seu lugar. A autora argumenta que o personagem pode (e deve) ter o poder de fazer o leitor pensar $\mathrm{e}$ enxergar da mesma forma que ele (personagem) enxergaria seu mundo e pensaria sobre ele, numa identificação que abrange todos os assuntos, como religião, amor, guerra, ou qualquer coisa que componha o universo do personagem em questão (Woolf, 1924, p. 11). Assim, para a autora, o leitor vai tentando decifrar e entender o personagem através do que seria o seu próprio ponto de vista, interno à narrativa. $A$ mesma colocação é válida para outros meios, como o teatro, o cinema, a televisão e os games. Ao acompanhar uma narrativa, o público se coloca na situação do personagem, se identifica com ele, "vive" a estória como se fosse ele. Esse vínculo de projeção é muito forte em todos os meios, mas, como será discutido mais adiante, as características dos games intensificam as emoções que são mobilizadas nesse processo.

\subsection{Personagens em Games}

Assim como o cinema e a literatura, o game narrativo é uma mídia que conta uma estória, através de situações que envolvem personagens. Porém os games 
possuem peculiaridades em relação às outras mídias que implicam em uma interação mais rica. Zimmerman (2010) comenta que os jogos podem criar significados únicos para cada jogador, de um modo diferente de outras formas de narrativa. Como foi dito anteriormente, na literatura, no cinema ou no teatro, o público cria uma projeção simbólica no personagem. Porém, essa é uma projeção em que o leitor ou espectador não tem controle sobre como aquele personagem com o qual ele se identifica está agindo. $O$ público pode sentir-se como o personagem, colocar-se simbolicamente no seu lugar, mas, ao fazê-lo, ele estará "preso dentro" de um personagem que age à revelia da sua vontade. Já a narrativa interativa própria dos games permite que o jogador escolha os caminhos que deseja percorrer ${ }^{2}$. Branco e Pinheiro (2005) também definem os games como uma mídia que possibilita uma maior interação e destacam como o suporte digital permite enriquecer a experiência do usuário, tanto no nível emocional quanto no sensorial. Para eles, "O cinema, a TV, a literatura, os quadrinhos, a música, a conversa: tudo pode ser reunido nos games.".

A interatividade está por trás de uma peculiaridade dos games narrativos, que é a existência de personagens que podem ser definidos pelo modo de interação com o jogador. Na classificação mais geral, e mais conhecida, os personagens em games costumam ser separados em dois tipos básicos (Isbister, 2006): o Avatar ou player character (personagem jogável, ou PC) e o non player character (personagem não jogável, ou NPC). O termo avatar tem origem no sânscrito e significa encarnação ou incorporação de algum espírito em forma material, podendo existir entre o mundo material e o espiritual, fazendo assim uma ponte de comunicação entre ambos (Fragoso e Rosário, 2008). No caso do jogo, o avatar serve como ponte entre o mundo do real do jogador e o mundo do jogo, ele é tanto o personagem em si quanto o jogador que se projeta nele. Klevjer $(2006$, p. 87) faz uma definição bem ampla do que significa avatar, explicando-o como um instrumento ou um mecanismo que confere ao participante um corpo ficcional, ou seja, o jogador experimentará a narrativa através de um agente ficcional. Também para Lankoski (2010, p. 24), um avatar pode representar um personagem fictício e também determinar o que o jogador poderá ou não fazer, conforme as regras previamente estabelecidas pelo jogo. Por isso, Isbister (2006, p. 203) considera o avatar como o coração da experiência interativa com o jogo: ele é a interface através da qual o jogador terá a experiência física e social no mundo do jogo.

Durante um jogo, o jogador tende a estabelecer um vínculo emocional com seu próprio avatar (Fragoso e Rosário, 2008). Segundo Salen e Zimmerman (2004, p. 453) este vínculo não se dá por uma identificação direta, mas justamente através de uma consciência dupla que é característica da relação entre o jogador e o jogo. Ou seja, o jogador sabe que o avatar é sua extensão no mundo do jogo e, ao mesmo tempo, sabe que ele, jogador, está fora do mundo do jogo, tanto quanto o espectador de cinema ou de televisão sabe que não está dentro do filme, mas nem por isso deixa de se identificar com os personagens e se emocionar colocando-se no lugar deles. No caso do jogo, justamente porque o avatar é um objeto gráfico manipulável, a experiência do jogador pode tornar-se mais intensa e emocionalmente imersiva que nos outros meios.

\footnotetext{
${ }^{2}$ Evidentemente o jogador só pode fazer suas escolhas dentro dos limites estabelecidos pelos designers do jogo. Porém, quanto melhor projetado o jogo, mais o o jogador terá a impressão de liberdade para agir.
} 
O segundo tipo de personagem dessa classificação é o NPC, ou seja, aquele personagem que o jogador não controla. A relação do jogador com esse tipo de personagem é mais parecida com aquela que se estabelece em outros meios, como o cinema. Por ser "parte da estória", o NPC também afeta o envolvimento emocional em jogos narrativos. Assim como o avatar, todo NPC possui o seu papel social bem definido no jogo, o que é importante na condução da interação (Isbister, 2006, p. 225): o avatar em contato com um NPC poderá ter novas informações que lhe permitem ir em frente no jogo, além de estabelecer vínculos afetivos com situações e locais.

Para Isbister (2006, p. 228), os papeis sociais dos NPCs possuem três dimensões, que são:

a) Interdependência: esta dimensão trata dos objetivos e habilidades que os NPCs possuem no jogo. Por exemplo, um NPC que é companheiro ou motivador social;

b) Dinâmicas de poder: esta dimensão refere-se à primeira impressão causada pelo personagem, e às relações hierárquicas entre avatar e NPC;

c) Obrigações e investimentos: esta dimensão trata das conexões sociais préexistentes com o jogador, como por exemplo um NPC que, na narrativa, já está estabelecido como inimigo do avatar (ou, nos termos internos à narrativa, do personagem do jogador).

Essa contextualização dos NPCs é essencial para a relação do jogador com seu avatar. Quanto melhor a articulação dos três fatores apontados por Isbister (2006), mais coerentes e significativos podem ser os conflitos sociais que se estabelecem na narrativa. Para Lankoski e Björk (2008) a narrativa precisa ser um foco e uma premissa, em torno dos quais ocorre o conflito. Os autores expandem e adaptam esta ideia para o jogo. O exemplo citado como premissa de uma narrativa é o do romance de Shakespeare, Romeu e Julieta: um grande amor desafia até a morte. Como exemplo em um jogo, é possível citar a doença do pai dos dois meninos em Brothers: a Tale of Two Sons ${ }^{3}$. Assim que há esta premissa, é possível partir para outros passos que situam os personagens dentro da narrativa: no exemplo, os dois irmãos precisam ir em busca de uma cura. Durante todo o jogo existe o que os pesquisadores definem como orquestração, que trata de colocar personagens em oposição, criando entre eles pontos de conflito, ou em convergência, criando pontos de atração. No caso, a cumplicidade dos dois personagens irmãos, que se apoiam mutuamente durante todo o percurso converge com as intenções de alguns personagens e entra em conflito com as de outros. Essas oscilações direcionam a estória, conferindo lógica e ritmo à narrativa.

Apesar de concordar em princípio com a necessidade de conhecer bem esses elementos, assim como outras características definidoras dos personagens, Sheldon (2004, p. 39) se opõe à ideia de Egri (1960), para quem quanto mais conhecimento se tem do personagem, melhor será. Para Sheldon, alguns fatores podem não ser tão evidentes para quem trabalha com outros meios, mas fazem muito sentido no contexto dos jogos narrativos: personagens autoexplicativos tornam-se entediantes e não convincentes.

Em uma tentativa de criar um método para o design de personagens de games capazes de direcionar ao máximo o envolvimento do jogador com o gameplay,

\footnotetext{
${ }^{3}$ Starbreeze Studios e 505 Games, lançado em 2013.
} 
Lankoski e Björk (2008) usam os conceitos de reconhecimento (recognition), alinhamento (alignment) e fidelidade (allegiance). Essas ideias, baseadas no modelo original de Smith (1995), foram adaptadas da criação de personagens de literatura para a criação e contextualização de personagens de games. O reconhecimento é a parte do processo de construção do personagem relativa à definição de suas características físicas e sociais: sua aparência e seu comportamento. Uma vez que, no caso dos avatares, esses elementos estão (pelo menos parcialmente) nas mãos do jogador e não do game designer, Lankoski et al (2007 apud Lankoski e Björk, 2008) propõem que o reconhecimento é promovido, ou ampliado, pelos objetivos que o jogo propõe ao jogador, pelo escopo das ações que ele pode ou não realizar através do avatar, bem como pelas consequências das suas ações. $O$ alinhamento refere-se a como o personagem e o jogador estão relacionados em termos de controle e acesso à informação. Assim, é o alinhamento que permite o reconhecimento. Isso envolve os tipos de acesso oferecidos para o personagem, como pensamentos, ações ou afetos. É importante que o gameplay e a narrativa estejam estruturados para que o alinhamento seja bem elaborado. Em relação à estrutura narrativa, Lankoski e Björk (2008) identificam dois tipos de alinhamento entre o jogador e o avatar: por detecção ou melodramático. Games que promovem alinhamento por detecção são aqueles em que o jogador controla um único personagem e seu conhecimento sobre o mundo do jogo está restrito ao que é sabido por aquele personagem, conforme o fluxo narrativo. Em estruturas melodramáticas, o jogador controla mais de um personagem e tem mais informação que qualquer um deles poderia ter individualmente. A fidelidade trata de como o jogador avalia o personagem. Os autores avaliam que o jogador será fiel ao personagem conforme perceba que ele tem qualidades desejadas ou positivas. Isso pode ocorrer mesmo quando não há simpatia pelo personagem, e tanto com o PC quanto com NPCs. Duas estratégias de design facilitam o estabelecimento de fidelidade. Na primeira, as ações que o personagem pode realizar mudam conforme a narrativa avança. Tipicamente a gama ou o poder dessas ações aumenta, mas os jogos demandam que o jogador faça escolhas entre diversas possibilidades. Isso direciona as características do avatar conforme as preferências do jogador, favorecendo a identificação. Em uma outra vertente o game designer pode optar por não criar uma história pregressa para o PC, ou revelar o mínimo possível sobre ele. Isso facilita a fidelização, pois o jogador sente que é ele quem vai criando a personalidade do personagem durante o jogo.

Essas considerações ajudam a perceber como, durante o jogo, o jogador vai levar seus personagens a executar ações que são definidas por ele, mas também são limitadas pelo game design. Assim, o avatar sempre terá limites, possibilidades e objetivos a serem alcançados, mas é o usuário quem irá guiá-lo dentro da narrativa do jogo. De acordo com Lankoski et al (2008), as diferenças entre as ações realizadas por diferentes jogadores com um mesmo personagem mostram como as habilidades se alteram. Os autores comentam que, por isto, parte do design de um PC é feito pelo jogador. Ou seja, esta ideia coloca o jogador como participante da construção de seu avatar mesmo quando não há possibilidade de customização da aparência do mesmo, já que, por mais limitadas que sejam as opções, o jogador é quem define boa parte das ações e reações do avatar e elas são indicativos de sua personalidade. Para Sato (2007) os personagens possuem uma relação de comportamentos já programados, porém o jogador constrói um comportamento único para seu avatar durante o jogo. A autora 
comenta que o mesmo avatar, quando jogado por pessoas diferentes, ganhará um destino distinto conforme quem está no comando, pois cada jogador imagina o seu avatar a seu modo e terá uma maneira de conduzir sua história. É nesse sentido que se diz que cada jogador encontra uma estória diferente quando joga o mesmo jogo, e até mesmo um único jogador, quando volta a jogar um jogo narrativo, constrói uma nova estória.

Isbister (2006) considera que o vínculo emocional entre personagem (avatar) e jogador é avaliado e instituído a partir da experiência do mundo real. Em seu trabalho sobre personagens de jogos, a autora considera as questões psicológicas da construção de personagens, dividindo os princípios psicológicos em dois tipos:

a) Socialização e dominância: este princípio trata das necessidades humanas, que a autora pré-estabelece conforme a Pirâmide de Maslow. Assim como na vida real, um personagem de game sempre estará envolto em alguma hierarquia social, na qual procura manter sua posição ou tenta posicionarse melhor.

b) Personalidade: a personalidade é definida por um conjunto de características como abertura, conscienciosidade, extroversão, afabilidade, e neuroticismo.

Lankosky (2010, p.13) defende que o uso de personagens aumenta a relação emocional do jogador com o jogo. Para ele, uma das funções básicas dos personagens é gerar conflitos sociais no mundo do jogo, o que motiva as respostas afetivas aos eventos dos quais o jogador participa através de seu avatar.

\subsection{Personagens em Games e Emoção}

O vínculo entre os jogadores e os personagens (avatares e NPCs) é essencialmente emocional. Um trabalho particularmente interessante a esse respeito é o de Palmer (2004), que se dedicou ao estudo das emoções de personagens, na abordagem que ele denomina "mentes ficcionais". Neste movimento, ele estuda também as emoções ficcionais e, para isso, parte do conhecimento estabelecido sobre as emoções "reais". Palmer se concentra sobre o trabalho de Antonio Damásio, que considera mais próximo da problemática das emoções nas narrativas. Vem de Damásio a distinção que ele faz entre emoções primárias, emoções secundárias e emoções de fundo, sendo as primárias:felicidade, tristeza, medo, raiva, surpresa e desgosto. As secundárias, ou sociais, seriam constrangimento, ciúme, culpa, orgulho. As emoções de fundo incluem bem-estar, relaxamento, instabilidade, etc. Palmer (2004, p. 114) também aponta que emoções se estendem por períodos variados de tempo: quando duram por um curto período, ele as considera um "evento emocional"; quando têm duração média, são consideradas "estados de espírito" (mood); e quando duram por um longo período podem estar relacionadas à própria natureza do indivíduo. Norman (2004) transpõe essa classificação da emoção para o Design Emocional ${ }^{4}$, em uma tipologia em três níveis. Para Norman, cada um desses níveis requer um estilo de design diferente:

a) Nível visceral: este é o nível básico de ação e reação, em que dominam os sentidos físicos - olfato, visão, tato, audição (Norman, 2004, p. 21). No

\footnotetext{
${ }^{4}$ Vale indicar que os três níveis propostos por Norman para o Design Emocional não correspondem diretamente aos três tipos de emoção descritos por Damásio. 0 detalhamento das diferenças entre essas duas classificações não será realizado pois escapa aos objetivos deste artigo.
} 
design voltado para o nível visceral é preciso trabalhar questões relativas à percepção e aos sentidos, por exemplo a forma, cores, texturas, etc. (2004, p. 65).

b) Nível comportamental: trata-se do nível de ação não consciente, que o autor exemplifica com o ato de alguém dirigir um carro enquanto pensa em algo completamente diferente (Norman, 2004 , p. 23). O design para este nível foca no uso e na performance (2004, p. 69).

c) Nível reflexivo: neste nível há consciência das ações que estão sendo realizadas (Norman, 2004 , p. 23). O design para este nível está relacionado a um grande número de questões, como a mensagem, cultura, significado, lembranças, evocadas (2004, p. 83).

O Design Emocional para games pode ser compreendido em duas vertentes: 0 Design Emocional do personagem e o Design Emocional para o jogador. No primeiro caso, trata-se de estabelecer parâmetros nos níveis visceral, comportamental e reflexivo internamente ao universo da narrativa, compondo a experiência emocional do personagem. O foco principal talvez esteja, entretanto, no Design Emocional para o jogador, ou seja, na criação das emoções que devem ser produzidas durante o gameplay. Esse segundo ponto, que parte do jogo mas se projeta para fora dele, também envolve os três níveis descritos por Norman (2004).

Pittermann et al (2010, p. 20) partem do trabalho de Sherer (2000) para diferenciar emoção de outros estados afetivos, classificando os estados afetivos da seguinte maneira:

a) Emoções (Emotions). Exemplo: raiva, desespero, orgulho.

b) Humores (Moods). Exemplo: alegria, apatia, irritação.

c) Posturas interpessoais (Interpersonal stances). Exemplo: distanciamento, frieza, solidariedade.

d) Preferências/Atitudes (Preferences/Attitudes). Exemplo: gostar, amar, odiar.

e) Disposição de sentimento (Affect dispositions). Exemplo: nervosismo, ansiedade, hostilidade.

Para Pittermann et al (2010), esses estados podem se alternar e apresentam variações conforme fatores como intensidade, duração, sincronização, foco no evento, impacto de comportamento, entre outros. Existem diferentes teorias que categorizam as emoções e tentam explicar como elas funcionam. Pittermann et al (2010, p. 22) aponta algumas delas, por exemplo a de James-Lange, que equaciona emoções a sentimentos. De acordo com essa teoria, sentimentos e emoções são interpretações que o cérebro constrói em resposta a uma configuração fisiológica. Assim, o medo, por exemplo, seria uma resposta ao aumento dos batimentos cardíacos diante de uma ameaça, e não o inverso ${ }^{5}$. Assim que o cérebro processa cognitivamente esta resposta fisiológica, a pessoa torna-se ciente da emoção. A teoria de Cannon-Bard contrasta com a anterior, sugerindo que, assim que ocorre o estímulo, ocorre a resposta emocional que deflagra o processamento cerebral produzindo respostas fisiológicas e emoções de forma simultânea e paralela. O sentimento da emoção e a reação visceral

\footnotetext{
${ }^{5}$ Esta teoria guarda relações com a diferenciação entre emoções e sentimentos formulada por Antonio Damasio, para quem as emoções são respostas a reações fisiológicas (aumento dos batimentos cardíacos, dilatação de pupilas, alteração no fluxo dos neurotransmissores, por exemplo). Já os sentimentos são o resultado da experiência subjetiva dessas respostas emocionais
} 
emergem juntos. Uma terceira teoria mencionada por Pittermann et al (2010, p. 23) é a de Shachter-Singer. Conhecida como "Two Factor Theory" ela considera que a emoção não nasce apenas de estímulos e respostas fisiológicas, mas envolve fatores cognitivos, rótulos que são atribuídos conforme o sujeito alimenta a sensação fisiológica com dados sobre a situação em que se encontra.As formas de projeção e identificação psicológica com os personagens de games mencionadas na seção anterior deste texto envolvem relações emocionais que guardam semelhanças com as que se estabelecem com os personagens de outras formas narrativas e também são diferentes delas. O caso especial do avatar constitui-se justamente porque o game é um sistema dotado de interatividade, ou seja, o jogador controla um dos personagens que habita o mundo ficcional. À parte o que já foi considerado, isso implica também a existência de interfaces tecnológicas, tanto físicas quanto imateriais, que permitem a interação entre o jogador e os personagens de um game. Assim, o Design de Games, e o Design de Personagens para Games, envolvem também um outro aspecto do Design Emocional, que é sua intersecção com o Design de Interfaces. Com a superação dos paradigmas mais antigos de abordagem da relação entre os usuários e os computadores, o Design de Interfaces passou a incorporar conhecimentos sobre psicologia, usabilidade, design de interação, design visual, etc. Atualmente, o Design da relação entre os usuários e sistemas interativos em geral está muito próximo do Design Emocional, sobretudo em sua vertente denominada Design de Experiência do Usuário.

Palmer defende que as emoções têm um papel cognitivo, ou seja, as emoções não são totalmente irracionais. Ele exemplifica com a situação de um nadador que vê um tubarão e sente medo. A emoção do medo vem de processos cognitivos (saber da possibilidade de ser mordido pelo tubarão) e envolve tanto as reações fisiológicas, os sentimentos e as ações (respectivamente, por exemplo, o aumento da pressão sanguínea, o horror e afastar-se do tubarão). Nesse caso, "a emoção do medo (...) é uma resposta racional e apropriada à situação" (2004, p. 116). O autor vai também vai ao encontro da ideia de que a cognição quase sempre possui algum componente emocional. Esses dois aspectos têm relação com a percepção de Isbister (2006) sobre a relação emocional que se estabelece entre um jogador e seu avatar, que a autora estratifica em quatro camadas (2006, p. 204). São elas:

a) Visceral - quando a pessoa experimenta o mundo através dos sentidos. No jogo, ela adapta seus sentidos da vida real para os do personagem e reage aos estímulos do mundo do jogo como reagiria aos do mundo real;

b) Cognitiva - quando o jogador não reage de maneira simples e automática aos estímulos sensoriais, mas considera as informações que recebe e avalia quais decisões e ações tomar;

c) Social - relativa a interpretações do mundo social, como reconhecer vozes e rostos conhecidos, que permitam identificar nuances do contexto social em um jogo.

d) Fantasia - avatares são tidos como importantes componentes de experiências fantasiosas. Em geral, os avatares mais poderosos são os que têm potencial para se conectar a muitos jogadores, através de esperanças da vida pessoal, medos e questões cotidianas, possibilitando que jogadores possam explorar possibilidades num mundo fictício.

As três primeiras estão claramente relacionadas às categorias propostas por Norman (2004), descritas anteriormente. A última é própria da situação ficcional. 
Alguns recursos característicos do Design de Personagens combinam todas essas formas de relação emocional. É o caso da opção por formas que remetem aos traços de rostos de bebês, as chamadas babyfaces. Figuras com caras de bebês causam no público uma sensação de acolhimento e de cuidado, uma relação visceral que pode se desdobrar, em um game, em alterações nas relações cognitivas e sociais (o jogador tende a proteger o personagem babyface, por exemplo). Segundo Isbister, a relação com a aparência dos personagens envolve desde características físicas até posturas e gestos, e as emoções desencadeadas por estes atrativos fazem parte do processo evolutivo (Isbister, 2006, p. 8). Outro exemplo que aparece na obra de Isbister é o dos estereótipos (2006, p. 13), que, segundo a autora, possuem um propósito importante de ajudar as pessoas a fazerem avaliações rápidas sobre pessoas, sobrepondo à necessidade de julgamentos racionais sobre todos os personagens e situações. Tanto os estereótipos quanto os personagens criados com maior sutileza mobilizam sensações e emoções que envolvem não apenas seus traços, mas também suas expressões faciais, seus movimentos, voz, etc. Segundo ela, jogadores podem se envolver em aprendizado social na interação com personagens bem elaborados, assim como o fazem com pessoas na vida real (Isbister, 2006 p. 143).

Em suma, pode-se dizer que através de seu avatar o jogador passa a fazer parte de um contexto social, o do mundo do jogo, com o qual estabelece uma relação que envolve as diferentes facetas das emoções. Por sua vez, cabe tanto ao Design do Game quanto ao Design dos Personagens orquestrar o papel social e as emoções que o jogador deverá (ou poderá) vivenciar durante o jogo.

\section{CONCLUSÃO}

Como fechamento deste texto, recuperam-se os elementos indicados pela literatura, organizando-os em temas e tópicos. As definições e considerações sobre cada tópico não serão retomadas nesta seção, pois já foram desenvolvidas no texto. Esse modo de apresentação pretende ser um framework de referência e apoio para a criação de personagens para games narrativos, com vista a torná-los mais envolventes e intensificar a experiência emocional do jogador. A mesma grade de referência pode ser utilizada como instrumento de avaliação para personagens já existentes.

a) Elementos para a a composição de um personagem (Egri, 1960)
a.i. fatores fisiológicos
a.ii fatores sociológicos
a.iii fatores psicológicos

b) Tipos básicos de personagens em games (Isbister, 2006)

b.i. player character (PC) ou avatar

b.ii. non-player character (NPC)

c) Papeis sociais dos NPCs (Isbister 2006)

c.i. interdepedência

c.ii. dinâmicas de poder

c.iii. obrigações e investimentos

d) Fatores de envolvimento com personagens (Lankoski e Björk, 2008)

d.i. reconhecimento

d.ii. alinhamento

d.iii. fidelidade

e) Aspectos psicológicos dos personagens (Isbister, 2006) 

e.i. socialização e dominância
e.ii. personalidade

f) Tipos de emoções (Palmer, 2004)

f.i. primárias

f.ii. secundárias

f.iii. de fundo

g) Níveis emocionais (Norman, 2004)

g.i. visceral

g.ii. comportamental

g.iii. reflexivo

h) Estados afetivos (Pittermann et al 2010)

h.i. emoções

h.ii. humores

h.iii. posturas interpessoais

h.iv. preferências e atidudes

h.v. disposição de sentimentos

i) Relação emocional entre jogador e avatar (Isbister, 2006)
i.i. visceral
i.ii. cognitiva
i.iii. social
i.iv. fantasia

Essa listagem deve ser levada em conta com o apoio das considerações e definições apresentadas nas seções anteriores do texto. Embora longe de ser completa, constitui uma primeira grade de referência que supre uma lacuna importante para a prática do Design de Personagens. Como tal, pode ser utilizada como ponto de partida para a criação de personagens tanto quanto como na avaliação de personagens já existentes.

Futuros trabalhos deverão refinar esse framework através do aprofundamento da conceituação utilizada para sua construção; do refinamento dos temas, tópicos e sub-tópicos; da testagem da grade com personagens já existentes e da criação de personagens utilizando-a como ponto de partida.

\section{REFERÊNCIAS}

BRANCO, Marsal Alves; PINHEIRO, Cristiano Max Pereira. Entre Combos e Enigmas. Sessões do Imaginário, Porto Alegre, v. 14, dezembro/2005 2005.

EGRI, Lajos The art of Dramatic Writing: Its Basis in the Creative Interpretation of Human Motives. New York, NY: Simon \& Schuster, 1960.

FRAGOSO, Suely. ROSÁRIO, Nísia Martins. Melhor Que Eu: um estudo das representações do corpo em ambientes gráficos multi-usuário online de caráter multicultural. Interin 70 (Curitiba), v. 6, p. 3, 2008. Disponível na internet por http em: <http://interin.utp.br/index.php/vol11/article/view/89>. Acesso em 17 abr. 2014.

GOFFMAN, Erving. A Representação do Eu na Vida Cotidiana. Petrópolis: Vozes, 1985.

ISBISTER, Katherine . Better game characters by design: a psychological approach. São Francisco: Elsevier Inc, 2006. 
KLEVJER, Rune. What is the Avatar? Fiction and Embodiment in Avatar-Based Singleplayer Computer Games. University of Bergen, 2006. Disponível na internet por http em: <http://characters.media.mit.edu/Papers/aisb99.pdf>. Acesso em 17 abr. 2014.

LANKOSKI, Petri. et al. A Method for Designing Multifaceted Player Character in Computer Games. Interactive Embodied Emotional Experience, Art \& Design, 2007, p. 72-75.

LANKOSKI, Petri. BJÖRK, Staffan. Character-Driven Game Design: Characters, Conflict and Gameplay. Liverpool: GDTW Conference, 2008. Disponível na internet por http em: <http://www.academia.edu/175264/Character-

Driven Game Design Characters Conflict and Gameplay>. Acesso em 17 abr. 2014.

LANKOSKI, Petri. Character driven game design: A Design Approach and its Foundation in Character Engagement. Aalto University: WS Bookwell Ltd, 2010

NORMAN, Donald. Emotional Design. Why we love (or hate) everyday things. Nova lorque: TLFeBOOK, 2004.

PALMER, Alan. Fictional Minds. Lincoln: University of Nebraska Press, 2004.

PITTERMANN, Johannes et al. Handling Emotions in Human-Computer Dialogues. Ulm: Springer, 2010.

SALEN, Katie. ZIMMERMAN, Eric. Rules of Play: Game Design Fundamentals. Londres: MIT Press. Cambridge: MIT Press, 2004.

SATO, Adriana. O caráter interpretativo da representação de personagens no Videogame. SBGames, 2007. Disponível na internet por http em: <http://www.sbgames.org/papers/sbgames07/artanddesign/full/ad6.pdf >. Acesso em 17 abr. 2014.

SHELDON, Lee. Character development and storytelling for games. Boston: Thomson Course Technology PTR, 2004.

SMITH, Murray . Engaging characters: Fiction, emotion, and the cinema. Nova lorque: Oxford University Press. 1995.

WOOLF, Virginia. Mr. Bennett and Mrs. Brown. Londres: Hogarth Press, 1924.

ZIMMERMAN, Eric. Narrative, Interactivity, Play, and Games: Four naughty concepts in need of discipline. Eric Zimmerman website, 2010. Disponível na internet por http em: <http://www.ericzimmerman.com/texts/Four Concepts.html>. Acesso em 17 abr. 2014. 